(he writes) argued that the interference of Sir George Grey wous repugnant to the governors of Bethlehem; that the present site was open and well suited for a lunatic asylum or a hospital. Dr. Hood concurred, and asked, how could the patients be taken ten or twenty miles into the country? Dr. Wood said that the building wous handsome, and the hospital healthy, and the grounds sufficiently large. There is, we take it, no need for us to refute such statements as these. They really amount to absolutely nothing; and, in fact, indicate prolty clearly the weakness of the cause in whose defence they are adduced. The only really valid argument which can be suggested in defence of Bethlehem Hospital remaining where it is, is simply the fact of its existence there- a money question. It does, we confess, surprise us to find gentlemen deeply conversant with lunacy bold enough to affirm that lunatics confined, immured betwoeen high walls, with no rural occupations, with none of the happy employments of life which are open to them in the country, are in as good a position as they might be. They seem to have argwed us if the mental and bodily occupation of these wretched creatures were a thing of no account. The site is healthy; what more can you desire? How are the lunatics to be got to a hospital ten miles from London? asked Dr. Hood. And said Dr. Wood, the patients at Bethlehem have more space per head thax have the patients at Hansoell with their twenty-eight acres and a farm of seventy-seven acres; therefore, the patients are better off and happier at Bethlehem, immured within its lugubrious walls, than they are whilst merrily planting cabbages at Hawwell?']

\title{
Dr. Richardson's Report on the Stafford County Lunatic Asylum, and on the Coton Hill Lunatic Hospital.
}

(From the "Medical History of England," by Dr. B. W, Richardson. 'Medical Times and Gazette,' March 12, 1864.)

"Whatever other disadvantages Stafford may labour under, there are very few towns that have so admirably conducted an asylum. The County Lunatic Asylum, situated about a quarter of a mile from the town itself; affords accommodation for $\mathbf{5 0 0}$ inmates. It is a noble building, and is as perfect in its internal arrangements as in its external appearance. Through the kindness of Dr. Bower, the superintendent-in-chief, I was enabled to make a careful inspection of every part of the asylum, and was supplied with numerous particulars of great interest to the profession at large.

\section{Ventilation-Haden's System.}

Not to dwell on the arrangements of the various wards, I may begin by referring to the system of ventilation. This is artificial, and is framed on the plan known as "Haden's." The air is forced in from the lower part of the building by means of steam, and steam is allowed to mix with the air on its entrance. Thus charged with moisture, the air is conveyed through iron shafts to all parts of the building, and enters into the wards and rooms at the upper part near to the ceiling. It escapes by a series of openings into shafts of similar size and construction at the lower part of the wards or rooms, and is drawn into a common shaft, situated at the upper portion of the building, by means of a fire shaft, 80 as to ensure for it a constant current and exit. The system works well, and I note the fact specially because it is almost the only plan of artificial ventilation which can be seen in effective action. In principle this ventilation is analogous to that known in Paris as "Duvoir's method." The differences are two in number. In Duvoir's 
plan, instead of the fire shaft in the upper part of the building, there is an immense cistern of hot water, which causes sufficient radiation of heat to produce draught, and at the same time affords a current of hot water, which, passing downwards through pipes, gives warmth to the various apartments. Warming is in this way combined with ventilation, a combination that is not attempted in Haden's system, the warmth of the establishment being provided for by the open fire-grate. Again, by Duvoir's plan the air is not admitted with steam, while in Haden's plan steam enters with the air. I was anxious to learn whether any of those evils common to the German method of driving beated air through iron pipes, and to the method of heating with iron stoves, were presented; I allude to the mischiefs arising from extreme dryness of the air and from the diffusion of minute particles of iron. On inquiry, I found that these evils were not present, and certainly it would be impossible to imagine in any room a purer and less objectionable atmosphere than that in the wards of the Stafford County Asylum. I think we may safely conclude that the English system is the best, and perhaps we may attribute its success to the admission of water vapour with the air, and to the fact that warming is effected by the open fire-grate. The object of letting in the air at the upper part of the rooms and of letting it escape at the lower, is to allow the current of air, in passing, to sweep away with it all offensive matters, and to keep pure that portion of air in which the patient is placed.

\section{Baths.}

There is an improvement in the Stafford County Asylum in the construction of baths. These are made of cast-iron instead of wood, tin, or earthen. ware. They are painted on their inner surfaces, and are not only very clean, but exceedingly durable. They are extremely economical in the long run, and for large establishments are preferable to the other kinds of bath. The Profession is indebted to Dr. Bower for this improvement.

\section{Beds and Bedsteads.}

The beds are of horse-hair, and there is a method for changing the webbing which is gaining favour in other asylums, and which might advantageously be introduced into hospitals generally. The webbing, of strong cloth, is not permanently attached to the bedstead, but can be removed altogether, whenever it is dirty or saturated with fluids, and replaced in a few minutes. The webbing is tightened up to any convenient tension by means of screws, which are worked from the outer edge of the bedstead on each side.

\section{J)ecorative Art.}

The asylum is like a palace in respect to its decorations. Real palaces may be immensely more costly, but could hardly be more artistic. Every available space is occupied by some artistic production that is at once pleasing or instructive. Pictures line every wall, flowers are in abundance, and, in some of the larger corridors, doves and other birds and animals are allowed to live in large handsome cages. The mouldings, also, of the walls, the colouring, and the cornices are simple and yet very pretty. In a word, for cleanliness, purity of air, and embellishment, nothing is left to be wished for; and if the inmates who are thus nourished through the senses are not, as Wordsworth puts it-

" healed and harmonised

By the benignant touch of love and beanty,"

their malady is confirmed indeed. The governors of the Stafford County 
Hospital should step across to the Stafford County Asylum; they might gain a whole forehead of wrinkles for their trouble.

$$
\text { The Asylum Farm-Value of Sewage. }
$$

Those of our brethren-and there are not a few of them-who blend the pursuit of agriculture with the art of physic should see the small farm that is connected with the asylum, and which is farmed on model and economical principles by Dr. Bower. The farm, worked to a great extent by the inmates, yields valuable contributions to the house, and they have been greatly increased of late by the utilisation of the sewage. The sewage of the gaol is now also collected in the asylum tank, and is applied, with that from the asylum itself, to the farm. The excretes from 1400 persons are thus utilised. The whole is first received into an immense tank, and is diluted in 1800 parts of water. Thus diluted, it is applied in limited dressings over the land, which, by the way, is all pasture land. Two tons of grass per acre is the produce-an increase double what the land would be worth for grass, if the sewage were not utilised as it is. Dr. Bower is of opinion-and his practical and careful experience is of much value in this matter-that the dilution of the sewage, and the employment of it in moderate quantities, are all-inportant as means of success. In this point of view his observations tend strongly in favour of the correctness of Mr. Ellis's method for the employment of the sewage of London.

\section{Practics of the Asycux.}

In the practice of the asylum non-restraint is now carried out so fully that even seclusion and the use of the padded room are ignored. No patient has been shut up for two years past. The cases admitted are numerous in type; but unusually large numbers of sufferers from insanity and general paralysis are present. Acute mania affords the greatest number of cases ; ordinary mania the next largest, and dementia the next still. Instances of puerperal mania are much more frequent than would at first be supposed no less than fifteen females having been admitted for this complaint in the year 1862 alone. The connection of disease of the body.previous to the development of mental disorder is broadly marked. Thus in the year 1862 not more than twenty-eight patients, out of two hundred and twenty-six admitted into the house, were pronounced, on entry, as in "good health and condition." Thirty-one were sufferers from epilepsy, twenty-seven from paralysis, thirty-one from disease of brain, ten from puerperal disease, seven from pulmonary consumption, and fifty-four from general exhaustion. It would be important in all cases to note, as a further addition to Dr. Bower's able examinations of cases on entry, the precise condition of the urine, with special reference to the questions of the elimination of phosphates and of sugar.

The numbers of recoveries that take place are considerable; in the year 1862 they amounted to $62 \cdot 75$ per cent. on the admissions for that year. The mortality is comparatively small. In the year named above, although the infirmaries were filled during the summer months with cases of paralysis and other affections of the brain, the mortality was but 8.19 per cent. on the total number under treatment. Paralysis was the cause of death in more than a fourth of the cases that terminated fatally, while about a fifteenth died from old age-senile decay. The reason for this low mortality is found in the freedom of the establishment from endemic and epidemic disorders. In point of fact, there are no such indices of what can be achieved by perfect sanitary regulations as the great lunatic asylums of voL. IX. 
England, and I was much amused once at hearing this fact referred to by an inmate of an asylum. Visiting the asylum at Lincoln a few years ago, I met there a patient who had once been a member of the medical profession, and who, full of talk and nonsense, said now and then a very good thing. Amongst other arguments-for, like one of the heroes of 'Midshipman Easy,' he delighted in the opportunity of undertaking to argue out every point-he insisted on the immense advantages of being insane. "George the Third was a fool, Sir, till he was mad; never had a moment's happiness or peace, Sir, till he was mad. Neither had I. Now, I'm a gentleman, and these folks who work here all run after me, and wait on me, while I look on and think how jolly it is to see what fools they are. I always say they are mad, and I am sane; and I'm right-ain't I, now, eh P'" Then, turning to the asylum (for this conversation took place in the grounds), he assumed a profound medical air, cocked up his chin, pursed his mouth, and added,

"Then, your cholera, and your smallpox, and fever; we've none of them in our house-they are for the fools outside. Why don't you go mad, and get awny from them, and make other people work for you, and be jolly and come here-eh ?"

The causes of insanity are carefully investigated at the Stafford Asylum. As each case is entered on the books a rigid inquiry is made as to cause. Alas! for Stafford county, it is not better than its neighbours. Intemperance, poverty and privation, and hereditary predisposition springing from these, are the great producers of its insane population. Year by year the same tale is told. Below we have the return of causes for 1860-an average return :-

\section{Casuse of Disorder.}

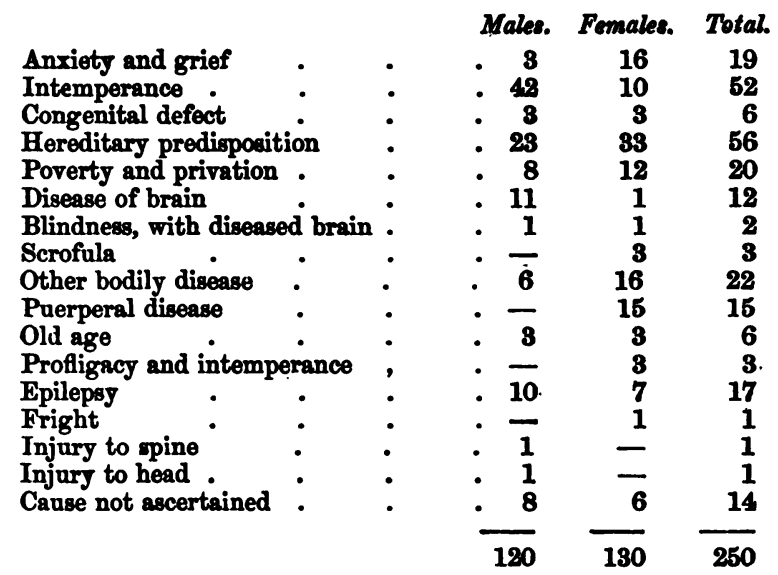

Cases of Singular Interest.

Asylum practice not uncommonly yields cases of peculiar interest, even in surgery. Dr. Bower was good enough to place before me several remarkable illustrations, of which I may note two or three. In one of these cases the patient, a female, æt. 43, retired one morning to a water-closet, after having secreted about her dress a pair of scissors, and before she could be prevented had time deliberately to make an opening into. her own 
abdomen, draw out some inches of the small intestine, cut the portion drawn out clean off, and throw it away. When Dr. Bower arrived he found two open ends of bowel protruding, and he endeavoured to bring them together by sewing their ends while in apposition. This direct object did not succeed; the open ends of the bowel became adherent to the wound in the walls of the abdomen, and an artificial anus was formed in the median line, midway between the umbilicus and pubes, through which the evacuations of the bowels were discharged. To the surprise of all, this woman recovered without a bad symptom, and some time afterwards she was discharged from the asylum cured of her insanity. Later in her life she was actually one day sent from her native place to the asylum either in charge of, or to fetch home, another patient. At that time she remained in bodily and mental health, suffering no further inconvenience than that from wearing a support, and of having to discharge the contents of the bowels through the artificial opening.

A patient was shown to me on the male side who had lost two fingersthe first and second of his hand-down to the second phalanges. The loss was occasioned, not by an accident, but positively from his having himself bitten the fingers off and eaten them. The operation appears to have been done almost unconsciously, and to have given rise to no pain. The wounds closed well, and the stumps are as perfect as if the amptutations had been conducted on the most improved surgical method.

A third case was that of a man who suffered from sloughing of the scrotum to such an extent that both testicles were exposed, and were for some weeks clearly dissected out, as it were, and pendant. The patient having improved in general health, the sloughing was arrested, reparation set in, and gradually the testes became invested in new tissue, until, at last, they were surrounded by what seemed like a new scrotum. It would have been difficult to discover, when the cure was completed, that new structure had been formed-the scrotum was 80 natural.

\section{Principles of Treatment.}

There is, as I have said, no seclusion nor coercion in the Stafford Asylum. Gentle work, and amusements of various kinds, such as music, dancing, exhibitions, cricket, football, \&c., are the means adopted for passing the time. At this moment there is in course of construction a spacious recreation hall, in which the patients will all dine together.

The diet is liberal; I think, however, it is a mistake to weigh it out-a mistake in economy and in feeling.

In the medicinal treatment of the insane, particularly during periods of maniacal excitement, Dr. Bower uses full doses of digitalis with great advantage. This remedy is of special value when there is disease and excitability of the heart. In these cases the digitalis acts like a charm; it produces calm without leading to sopor; it exerts no bad effects on the digestive functions, and it leaves no serious depression behind. Thus, it is far preferable to narcotics in cases for which it is suitable. The cannabis indica has been employed extensively as an anodyne, and occasionally its action is good, but it sometimes fails. On the whole, when opium is not administrable, the cannabis is less certain than hyoscyamus, which, when given boldly, is invaluable in the treatment of mental disease. As an opiate, a watery solution of opium is used in preference to the other forms of the drug.

Dr. Mark Noble Bower is the Resident Medical Officer and Superin. tendent, and Dr. Rubert A. Davis is the Assistant Medical Officer. 


\section{THE COTON HILL INSTITUTION FOR THE INSANE.}

Near to Stafford is another institution for the insane, called the Coton Hill Institution. This asylum is for the reception of two classes of insane patients, viz.- lst, patients in more or less affuent circumstances who shall contribute, according to the accommodation required, such weekly sum as may be agreed upon; and 2nd, patients in limited circumstances, though not paupers, who shall be received at such reduced rates of payment as the Committee, upon a considerntion of their circumstances, may in each case determine; the deficiency being made up out of the surplus moneys received from the patients of the first class beyond their actual cost, assisted by annual subscriptions, donations, and legacies. For every two guineas subscribed annually, subscribers are entitled, during payment, to recommend, subject to the powers reserved to the House Committee, one patient within the year for admission into the second class; donors have the same privilege during life for every twenty guineas.

'The medical officers attached to this institution are-a Visiting Physician, who receives a stipend of 100 guineas a year, and \& Resident Superintendent. The former office-now, I believe, vacant-has been held until recently by Dr. Wollaston, a relative of the great physicist of that name; the latter is held by Dr. Hewson."

\section{A Voice from Derby to Bedlam.}

"WITH the ostensible object of deprecating the langaage employed, and the arimus assumed to be felt, by the authors of a recent pamphlet on the Townley case, the author of 'A Voice from Derby' reopens the question as to the guilt or innocence of the murderer of Miss Goodwin, with the evident intention of vindicating the evidence as to his insanity given at his trial by Dr. Forbes Winslow. The able report to the Home Secretary, which finally decided the fate of Townley, 80 carefully drawn up by Dr. Bucknill, and endorsed by Dr. Hood, Dr. Meyer, and Dr. Helps, had, as we thought, set at rest for ever the question of Townley's sanity. The convict himself felt the searching force of the examination to which he was last subjected, and anticipated its result. 'They think me sane,' said Townley, as the commissioner left his cell ; 'still, it is very hard if they hang me now.' Although there is nothing $n e w$ in the pleas brought forward by the author of ' $A$ Voice from Derby, the question as to the insanity of Townley is treated with considerable ability; the manageable facts being dexterously handled, and ankward and damaging ones judiciously left unnoticed. Thus we are referred to the opinion of the counsel for the prosecution, that there was no evidence of any premeditation on the part of the prisoner; but the fact of Townley's having three knives upon his person-one a large clasp-knife, newly bought, the instrument with which the murder was committed-is not explained. We cannot say that the 'Voice from Derby' is distinguished by either temper or moderation; and we regret to find in it an attack upon an estimable provincial physician, whose talent and character should have protected him from such language. We cannot see anything in the conduct referred to that justified suchlanguage; and certainly the reproach cast upon that gentleman, that he has never been concerned in any of the great lunacy trials, is far from being any disgrace to him. He has at least escaped the imputation that so many have incurred; viz., of merging the medical witn 383 in the paid advocate. The 'Voice' takes great pains to vindicate 